\title{
The effect of ligands on the change of diastereoselectivity dimerization of 2-(naphthyl-1)cyclopropanedicarboxylate in the presence of $\mathrm{GaCl}_{3}$
}

\author{
Roman A. Novikov, ${ }^{\text {a,b }}$ Denis D. Borisov, ${ }^{\text {a }}$ Yury V. Tomilov ${ }^{a^{*}}$ \\ ${ }^{a}$ N. D. Zelinsky Institute of Organic Chemistry, Russian Academy of Sciences, 47 Leninsky \\ prosp., 119991 Moscow, Russian Federation \\ ${ }^{b}$ V. A. Engelhardt Institute of Molecular Biology, Russian Academy of Sciences, 32 Vavilov st., \\ 119991 Moscow, Russian Federation \\ E-mail: tom@ioc.ac.ru
}

DOI: https://doi.org/10.24820/ark.5550190.p009.860

\begin{abstract}
A new method to regulate the diastereoselectivity of reactions of donor-acceptor cyclopropanes by ligand control has been found. The method has been demonstrated for [4+2]cyclodimerization of 2-(1-naphthyl)cyclopropanedicarboxylate to give polysubstituted tetrahydrophenanthrenes in the presence of $\mathrm{GaCl}_{3}$ as an example. If tetrahydrofuran is used as the ligand, the trans,trans-isomer is formed exclusively, whereas if 1-formylpyrene is used, diastereoselectivity changes almost completely and the trans,cis-isomer is formed. A possible mechanism of diastereoselectivity change has been suggested and studied.
\end{abstract}

Keywords: Naphthylcyclopropanedicarboxylate, gallium trichloride, dimerization, 1,2zwitterion, ligand-control

\section{Introduction}

During the rather long history of studies on donor-acceptor cyclopropanes (DAC), they found an adequate and quite important place in modern organic chemistry and are now widely used in its various branches. ${ }^{1-21}$ Dimerization reactions are one of considerable achievements of the chemistry of DAC, primarily 2-arylcyclopropane-1,1-dicarboxylates. This is an interesting field where intense studies are currently performed, that allows substituted aliphatic ${ }^{22-24}$ or cyclic $^{22,23,25-27}$ structures with various regioselectivity to be assembled in one experimental stage from rather simple substrates. Special attention in DAC dimerization processes belongs to reactions involving annelation of the original 2-arylcyclopropane-1,1-dicarboxylates with a benzene ring. In these reactions, DAC can act not only as 1,3-dipoles ${ }^{28-30}$ but also as sources of formal 1,2-zwitter-ions formed due to positive charge "migration" induced by anhydrous 
$\mathrm{GaCl}_{3}{ }^{31}$ The regio- and diastereoselectivity of these reactions were generally very high. However, the stereochemical result of these reactions just confirmed the observed stereoselectivity but did not allow one to significantly control the isomeric composition of the resulting compounds. Perhaps there is only one example of process stereoselectivity change, namely, dimerization of 2-indol-3-yl- ${ }^{28}$ or 1-naphthylcyclopropane $\operatorname{diesters~}^{29} \mathbf{1 a , b}$ which involves electrophilic ipso-attack on aromatic ring that induces a cascade of transformations affording complex polycyclic systems $\mathbf{2}$ and $\mathbf{3}$ (Scheme 1). The most efficient process was found to be dimerization of 3-indolyl derivatives 1 a that occurs in the presence of $\mathrm{SnCl}_{4}$ with high diastereoselectivity and yields pentaleno[1,6-a,b]indoles $2 .{ }^{28}$ For 1-naphthyl derivative $\mathbf{1 b}$, the reaction occurs with the opposite diastereoselectivity under catalysis with $\mathrm{GaCl}_{3}$ together with an organocatalyst to give pentaleno[6a,1-a]naphthalene $3 .^{29}$ However, it should be mentioned that not only the reaction conditions, including the nature of the Lewis acid used, but also the type of the aromatic substituent were changed in these reactions.

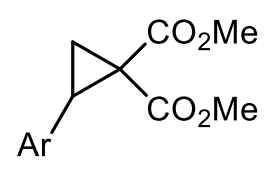

$1 a$

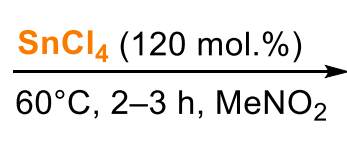

\section{$\mathrm{R}^{1}$}

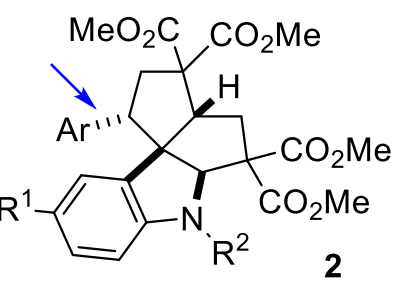

$\mathrm{Ar}=5-\left(\mathrm{R}^{1}\right)-1-\left(\mathrm{R}^{2}\right)-3$-indolyl; $\mathrm{R}^{1}=\mathrm{H}, \mathrm{F}, \mathrm{Cl}, \mathrm{Br}, \mathrm{CN} ; \mathrm{R}^{2}=\mathrm{Me}, \mathrm{Bn},\left(\mathrm{CH}_{2}\right)_{3} \mathrm{Ph}$

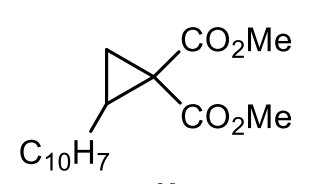

$1 \mathrm{~b}$

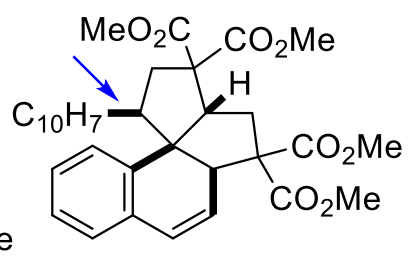

3

Scheme 1. Change of diastereoselectivity in the dimerization of 2-(3-indolyl)- and 2-(1naphthyl)cyclopropane-1,1-dicarboxylates 1a,b.

\section{Results and Discussion}

In continuation of this research, we studied the effect of various ligands and additives on the type of transformations of 2-arylcyclopropane-1,1-dicarboxylates induced by Lewis acids, and primarily on the behavior of 1,2-zwitterion intermediates formed upon opening of the threemembered ring in the presence of anhydrous gallium trichloride and migration of the carbocationic center. ${ }^{31,32}$ In this paper, we demonstrate for the first time the possibility to use ligands for stereo-controlled synthesis of two different diastereomers using the same substrate. 
We demonstrated this effect for [4+2]-cyclodimerization of 2-(1-naphthyl)cyclopropanedicarboxylate (1b) to give polysubstituted tetrahydrophenanthrene $\mathbf{4 a}$ as an example. In the standard procedure, 1 equivalent of anhydrous $\mathrm{GaCl}_{3}$ was first added at $0-5^{\circ} \mathrm{C}$, then 1 equivalent of tetrahydrofuran was added and the reaction mixture was stirred for $6 \mathrm{~h}$ at $20^{\circ} \mathrm{C}$. The use of tetrahydrofuran that decreased the Lewis acidity of $\mathrm{GaCl}_{3}$ affected the regioselectivity of the process as a whole and ensured a considerably higher yield (from 30 to 67\%) of the target product - tetrahydrophenanthrene $\mathbf{4 a},{ }^{31}$ which was formed exclusively as the trans, trans-isomer under these conditions (Scheme 2).

However, if one equivalent of pyrene-1-carboxaldehyde rather than tetrahydrofuran is used as the ligand, then the overall reaction direction remains the same and the yield of the target product is rather high, but its isomeric composition is different, i.e., the diastereoselectivity is changed almost completely in this case and tetrahydrophenanthrene containing $92 \%$ of trans,cisisomer $\mathbf{4 b}$ is obtained (Scheme 2).
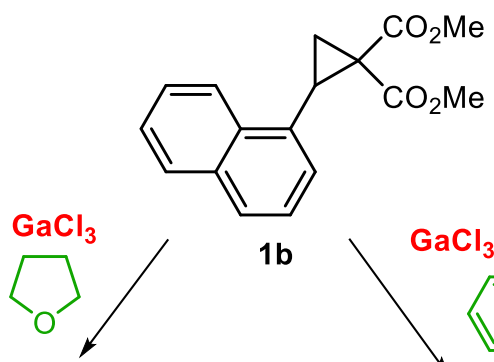

$1 b$
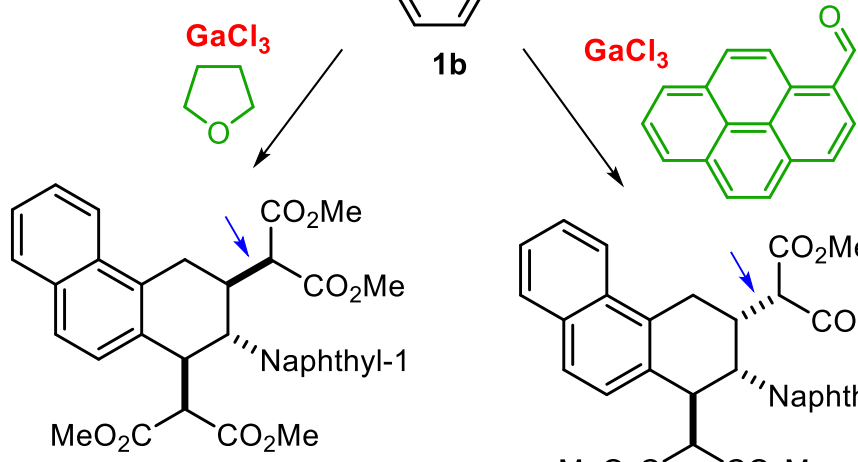

4a $(67 \%, d r>99: 1)$

Previous work:

Angew. Chem. Int. Ed.

2014, 53, 3187

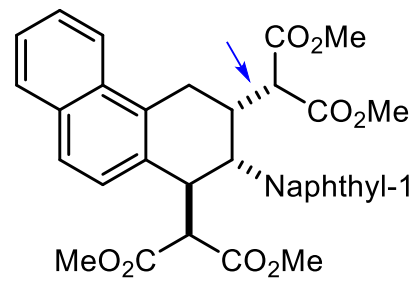

4b $(64 \%$, dr 92:8)

This Work

Scheme 2. Novel approach to the change of diastereoselectivity in [4+2]-cyclodimerization of $1 b$.

This effect of the ligand on the reaction diastereoselectivity appears quite remarkable and is undoubtedly of considerable interest in synthesis as it opens a way to control the diastereomeric composition of products in directed synthesis of compounds with a particular isomeric composition.

In fact, the majority of known DAC reactions occur with very high diastereoselectivity and many examples of enantioselective DAC reactions are also known. ${ }^{1-9}$ However, in all cases, the reaction diastereoselectivity was determined by the type of substituents, reaction type, etc., and it 
could not be altered at will. Therefore, the approach that we discovered appears quite important and valuable for subsequent development of DAC chemistry.

It is rather difficult to answer at this point why it is aromatic aldehydes that work successfully. From experimental point of view, it is a result of long and thorough studies on various ligands, additives, and substrates in reactions involving 1,2-zwitter-ions formation. Since this domain is quite extensive and has vague boundaries, we now focused only on a study of aromatic aldehydes and detailed tuning of experimental conditions. It should be noted that processes involving 1,2-zwitter-ion gallium complexes are very complex, ${ }^{8,23-25,29,31,32}$ and in general, various ligands and substituents in the starting cyclopropanes can considerably affect their chemical reactions.

Optimization of conditions of [4+2]-cyclodimerization of cyclopropane $\mathbf{1 b}$ and data on the effect of the nature of aromatic aldehydes on the diastereoselectivity of formation of trans,transtetrahydrophenanthrene $\mathbf{4 a}$ and trans, cis-isomer $\mathbf{4 b}$ are presented in Table 1. At first, a relatively stable 1,2-dipolar intermediate $\mathbf{5}$ is generated from cyclopropane $\mathbf{1 b}$ upon treatment with gallium trichloride at $0-5^{\circ} \mathrm{C} .^{32}$ It is then entered into the reaction with a second portion of cyclopropane $\mathbf{1 b}$ at $40^{\circ} \mathrm{C}$ in the presence of the corresponding ligand (method $\mathrm{A}$ ). In an alternative version of this process, instead of an additional portion of cyclopropane $\mathbf{1 b}$, intermediate $\mathbf{5}$ reacts with preliminary obtained isomeric 2-(naphth-1-yl)vinylmalonate $\mathbf{6}^{25,33}$ (method B). Both methods are quite similar in the reaction result and stereochemistry of products. However, method B was found to be more convenient because it was found to be less sensitive to the process conditions and gave somewhat higher product yields due to suppression of the side reaction of [3+2]cycloaddition of the cyclopropane to the aldehyde.

As noted above, diastereomer $\mathbf{4 a}$ was formed exclusively in the presence of THF (Table 1, Entries 2 and 3). It should be noted that diastereomer 4a was also the main product in the absence of THF, but its yield was much lower (Table 1, Entry 1) due to oligomerization side processes. ${ }^{31}$ It is interesting to note that the use of a sterically substituted tetrahydrofuran, namely dimethyl 2,5-diphenyltetrahydrofuran-3,3-dicarboxylate ${ }^{34}$ (Table 1, Entry 4), had nearly no effect on the diastereomeric composition of the target products. At the same time, the use of aromatic aldehydes as the ligands changed the diastereoselectivity of this reaction considerably (Table 1, Entries 5-11). The formation of tetrahydrophenanthrenes 4a,b in the presence of benzaldehyde or 1-formylnaphthalene was not selective at all (Table 1, Entries 5, 6 and 8). On the other hand, aldehydes with more bulky aryl substituents, such as anthracene-9carboxaldehyde and pyrene-1-carboxaldehyde, showed much better diastereoselectivity and the reaction resulted in a considerable prevalence of another diastereomer, namely, trans,cis-isomer 4b (Table 1, Entries 9-11). In the case of pyrene-1-carboxaldehyde, the ratio of diastereomers $\mathbf{4 b}$ and $4 \mathbf{a}$ was found to be 92:8, which appears to be rather a high value. It should however be noted that in the latter two cases, more drastic conditions $\left(80^{\circ} \mathrm{C}, 1 \mathrm{~h}\right)$ had to be used due to a strong decrease in the reactivity of the intermediate gallium complexes because of the considerable steric volume of the aromatic substituents in the aldehydes specified. 
Naphthylcyclopropanedicarboxylate $\mathbf{1 b}$ was not chosen at random, either. It should be noted that DAC themselves, 2-arylcyclopropane-1,1-dicarboxylates in particular, react rather readily with aldehydes in the presence of Lewis acids under various conditions. ${ }^{34-39}$ However, naphthylsubstituted cyclopropane 1b stands apart and slowly reacts with aldehydes. This fact allowed us to use it as an example in order to develop a diastereoselective control method to synthesize substituted tetrahydrophenanthrenes $\mathbf{4 a}, \mathbf{b}$ in the course of $\mathbf{1 b}$ dimerization.

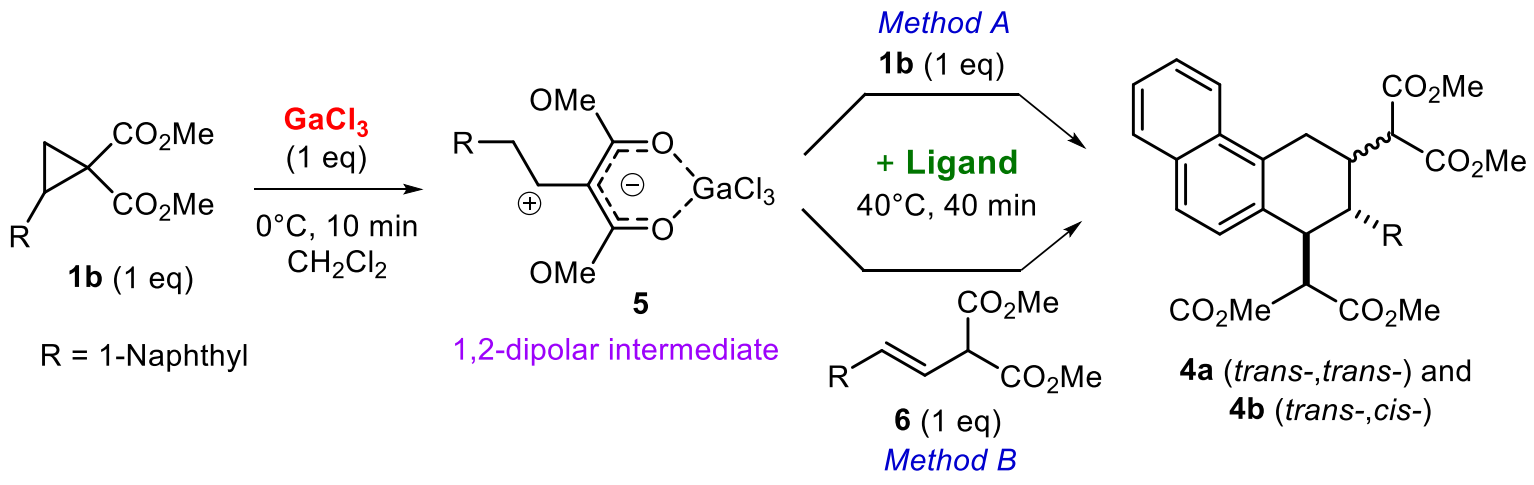

Table 1. Ligand effect on the diastereoselectivity of the model reaction of dimerization of $\mathbf{1 b}$

\begin{tabular}{|c|c|c|c|c|c|}
\hline Entry & Method & Ligand & Mol. ratio & Diast. ratio $\mathbf{4 a}: \mathbf{4 b}$ & Yield, $(\%)$ \\
\hline 1 & A & None & - & $>95: 5$ & $<20^{a}$ \\
\hline 2 & $\mathrm{~A}$ & THF & 1 & $>99: 1$ & 67 \\
\hline 3 & $\mathrm{~B}$ & $-/ /$ & 1 & $>99: 1$ & $70^{b}$ \\
\hline 4 & $\mathrm{~B}$ & & 1 & $>95: 5$ & $55^{\mathrm{b}}$ \\
\hline 5 & A & & 3 & $45: 55$ & $\sim 50^{b}$ \\
\hline 6 & B & $-/ /-$ & 3 & $40: 60$ & 67 \\
\hline 7 & B & - & 6 & $65: 35$ & $<50^{b}$ \\
\hline 8 & B & & 2.5 & $60: 40$ & $60^{b}$ \\
\hline 9 & B & & $1.5^{\mathrm{d}}$ & $12: 88$ & 65 \\
\hline
\end{tabular}


Table 1. Continued

\begin{tabular}{cccccc}
\hline Entry & Method & Ligand & Mol. ratio & Diast. ratio $4 \mathrm{a}: 4 \mathrm{~b}$ & Yield, (\%) \\
\hline 10 & $\mathrm{~A}$ & $1.5^{\mathrm{d}}$ & $20: 80$ & $45^{\mathrm{b}}$ \\
& & & & & \\
11 & $\mathrm{~B}$ & $-/ /-$ & $1.5^{\mathrm{d}}$ & $15: 85$ & $62^{\mathrm{b}}$ \\
12 & $\mathrm{~B}$ & $-/ /-$ & $1.2^{\mathrm{d}}$ & $\mathbf{8 : 9 2}$ & 64 \\
\hline
\end{tabular}

${ }^{a}$ Significant polymerization takes place; ${ }^{b}$ NMR yields. ${ }^{c}$ This compound was synthesized as described previously. ${ }^{34 \mathrm{~d}}$ Reaction conditions on the 2 nd step: 1,2 -DCE, $80^{\circ} \mathrm{C}, 1 \mathrm{~h}$.

The composition of the target products $\mathbf{4 a}$ and $\mathbf{4 b}$ was established by means of elementary analyses or HRMS. The structure and stereochemistry of the compounds obtained were determined by ${ }^{1} \mathrm{H}$ and ${ }^{13} \mathrm{C}$ NMR spectroscopy using 1D and 2D DEPT, COSY, TOCSY, NOESY, HSQC, and HMBC. Figure 1 shows the key differences between both diastereomers in the $2 \mathrm{D}{ }^{1} \mathrm{H},{ }^{1} \mathrm{H}-\mathrm{NOESY}$ NMR spectra.

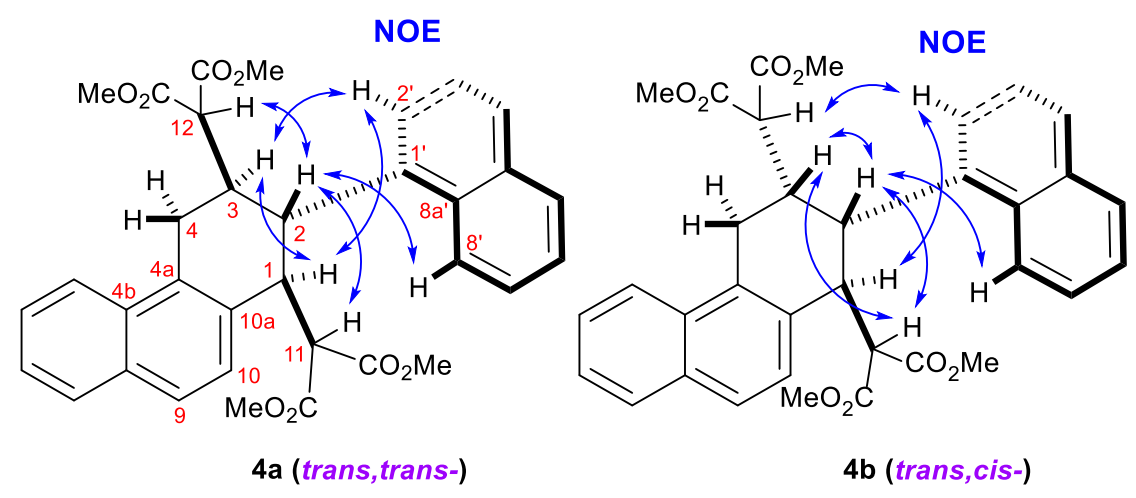

Figure 1. Key NOE cross-peaks in $2 \mathrm{D}{ }^{1} \mathrm{H},{ }^{1} \mathrm{H}-\mathrm{NOESY}$ NMR spectra for the stereochemistry assignments of diastereomers $\mathbf{4 a}$ and $\mathbf{4 b}$.

Based on the data obtained here and known previously, the following reaction mechanism and reasons of diastereoselectivity change by various ligands can be suggested (Scheme 3). The first stage of the process that involves generation of a 1,2-zwitter-ion gallium complex from a cyclopropane-1,1-dicarboxylate was described in detail in our studies. ${ }^{31,32}$ After that, the ligand comes into action. It is coordinated to the gallium atom of complex $\mathbf{5}$ and gives intermediates $\mathbf{7}$ with retention of the 1,2-zwitter-ion structure. Such coordination of ligands with 1,2- zwitterions of type 5 was studied by us in considerable detail previously; ${ }^{32}$ what is more, a 1,2-zwitterion complex formed from 2-phenylcyclopropanedicarboxylate with THF (similar to 7a) was 
detected and its structure was determined. ${ }^{32}$ Therefore, there is no doubt that intermediates 7 are formed in this process.

Intermediates $\mathbf{7 a}$ and $\mathbf{7 b}$ only differ in the nature of the ligand coordinated to the gallium ligand, therefore the subsequent fate of these intermediates is similar in a certain range of conditions: they undergo dimerization by [4+2]-annelation pathway to give the tetrahydrophenanthrene skeleton by coupling of 1,2-zwitter-ion intermediates $7 \mathbf{a}$ or $7 \mathbf{b}$ with $\beta$ naphthylvinylmalonate $\mathbf{6}$ formed upon isomerization of the second portion of cyclopropane $\mathbf{1 b}$, or by using a previously prepared sample. The reaction of 1,2-zwitter-ion 7 with $\beta$ naphthylvinylmalonate $\mathbf{6}$ where the double bond is polarized with partial negative charge on the benzyl carbon atom gives a new 1,2-zwitter-ion intermediate $\mathbf{8}$, in which the induced positive charge is stabilized due to intramolecular re-coordination of the malonyl moieties. In this case, the difference in the ligand structures dramatically affects the stereochemical outcome of the key step of $\mathrm{C}-\mathrm{C}$ coupling.

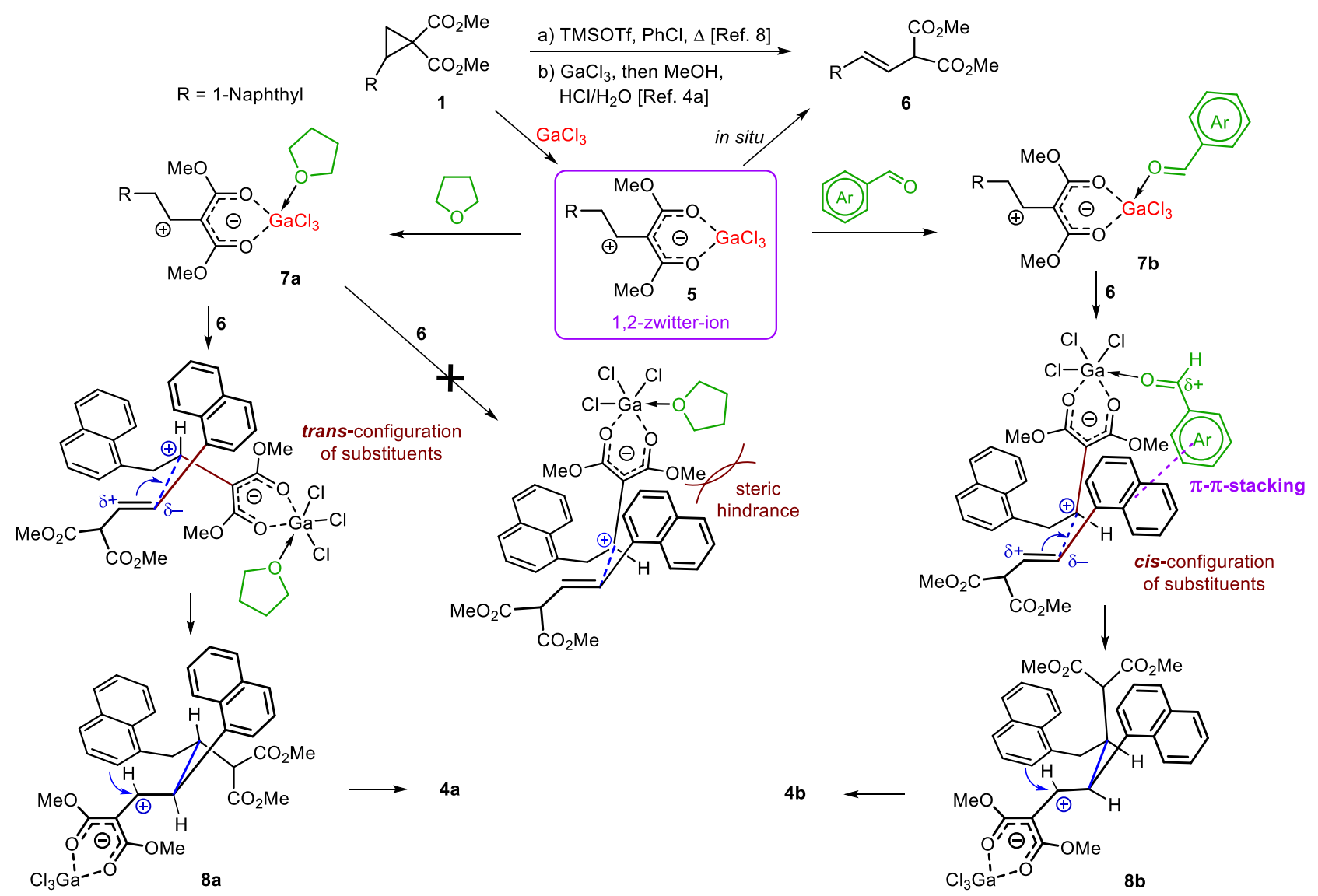

Scheme 3. Proposed mechanism and stereoselectivity of [4+2]-dimerization of cyclopropane $\mathbf{1 b .}$

When tetrahydrofuran ligands are used or if they are absent, the naphtyl and coordinated malonyl substituents are arranged in the trans-orientation (Scheme 3, intermediate 8a), since 
considerable steric hindrance takes place in the cis-orientation due to their large size, and the intermediate with the cis-arrangement of substituents is nearly not formed. In this case, stereochemical control is exclusively caused by steric effects of substituents.

On the contrary, when aromatic aldehydes are used as the ligands, the reaction occurs in violation of steric control, via the sterically unfavorable cis-orientation of the naphthyl and coordinated malonyl substituents in the transition state (Scheme 3, intermediate 8b), which actually manifests itself as the necessity of more drastic reaction conditions. In this case, the cisconfiguration of these substituents apparently arises from $\pi$ - $\pi$-stacking between the aryl substituents due to interaction between the $\pi$-systems of the naphthyl substituent in the substituted malonate and the aryl substituent in the aldehyde, which strongly favors their approach. Furthermore, the aromatic aldehyde molecule is polarized positively due to coordination with gallium, whereas the naphthyl substituent is polarized negatively, and the opposite polarization of both aromatic rings favors their stronger interaction. The version about $\pi$ - $\pi$-stacking was confirmed very well by varying a number of aromatic aldehydes (Table 1 ). The best diastereoselectivity values in the formation of trans,cis-isomer $\mathbf{4 b}$ are observed for aldehydes with a large $\pi$-system of a few fused benzene rings (Table 1, Entries 9-11). As the same time, a mixture of diastereomers is formed in the presence of "small" aromatic aldehydes (Table 1, Entries 5-8), i.e., the force of $\pi$ - $\pi$-stacking appears insufficient and the reaction is controlled to a considerable extent by steric factors. The version about the effect of the considerable steric volume, which also grows strongly with enlargement of the $\pi$-system, on diastereoselectivity change turns out to be invalid. In fact, a check experiment using a strongly loaded tetrahydrofuran ligand (dimethyl 2,5-diphenyltetrahydrofuran-3,3-dicarboxylate) (Table 1 , Entry 4) without a large $\pi$-system did not give noticeable amounts of trans,cis-isomer $\mathbf{4 b}$. Hence, the observed change in the process diastereoselectivity by aromatic aldehydes used as the ligands is due to the effect of $\pi$ - $\pi$-stacking of aryl substituents in the key transition state.

The assumed mechanism was partially studied and confirmed by monitoring the reactions in an NMR spectrometer at reduced temperatures. These experiments were found to be very difficult to perform due to the low stability of intermediate complexes, as well as their not-toogood solubility, strong lability to traces of moisture, and sensitivity to reaction conditions. Nevertheless, we succeeded in detection of a few intermediate dipolar gallium complexes at the first process stages $(\mathbf{5}, \mathbf{7 a}, \mathbf{7 b}$ with benzaldehyde, $\mathbf{7 b}$ with pyrene-1-carboxaldehyde) (Figure 2, Table 2).

In fact, we confirmed ligand coordination to the gallium atom without breakdown of the 1,2zwitter-ion structure to give the corresponding complexes (see Scheme 3). The primary complex 5 is relatively stable and exists for dozens of minutes in solution at $0-10^{\circ} \mathrm{C}$. Second generation complexes 7a,b are much less stable and decompose in a few minutes even at reduced temperatures. Decomposition occurs by a number of pathways that in many respects differ from reactions in a flask (since the conditions cannot be accurately reproduced in an NMR tube), which considerably complicates their study. 


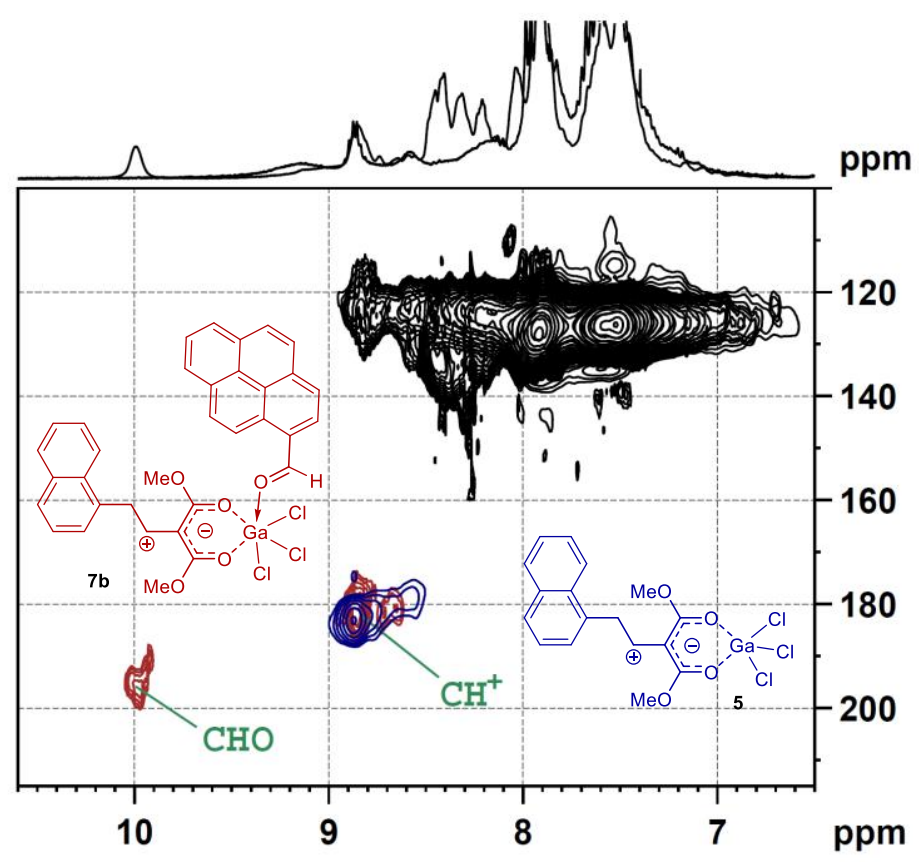

Figure 2. $2 \mathrm{D}{ }^{1} \mathrm{H},{ }^{13} \mathrm{C}-\mathrm{HSQC}$ NMR spectra (aromatic region) of intermediate Ga complexes 5 and $7 \mathbf{b}$ at $0^{\circ} \mathrm{C}$.

Table 2. Characteristic ${ }^{1} \mathrm{H}$ and ${ }^{13} \mathrm{C}$ NMR data of complexes $\mathbf{5}, \mathbf{7 a}, \mathbf{7 b}$

\begin{tabular}{llcccc}
\hline Complex & & $\begin{array}{c}\mathrm{CH}_{2} \\
\delta, \mathrm{ppm}\end{array}$ & $\begin{array}{c}\mathrm{CH}^{+} \\
\delta, \mathrm{ppm}\end{array}$ & $J(\mathrm{~Hz})$ & $\mathrm{CHO}$ \\
\hline $\mathbf{5}$ & ${ }^{1} \mathrm{H}$ & 4.86 & 8.86 & 6.0 & - \\
& ${ }^{13} \mathrm{C}^{\mathrm{a}}$ & 38 & 183 & - & - \\
$\mathbf{7 a}$ & ${ }^{1} \mathrm{H}$ & 4.3 & 8.55 & 7.0 & - \\
& ${ }^{13} \mathrm{C}$ & 41 & 179 & - & - \\
$\mathbf{7 b}^{-\mathrm{b}, \mathrm{c}}$ & ${ }^{1} \mathrm{H}$ & 4.86 & 8.85 & 6.3 & 9.90 \\
$\mathbf{7 b}^{\text {"-d }}$ & ${ }^{1} \mathrm{H}$ & 4.85 & 8.81 & 5.5 & 9.99 \\
& ${ }^{13} \mathrm{C}$ & 38 & 181 & - & 197 \\
\hline
\end{tabular}

${ }^{\mathrm{a}}$ Chemical shifts ${ }^{13} \mathrm{C}$ were determined from 2D HSQC spectra; ${ }^{\mathrm{b}}$ Data for ${ }^{13} \mathrm{C}$ were not obtained due to a low stability of the complex; ${ }^{\mathrm{c}} \mathrm{ArCHO}$ - benzaldehyde; ${ }^{\mathrm{d}} \mathrm{ArCHO}$ - pyrene-1carboxaldehyde.

The structures of the complexes were studied and confirmed by 2D COSY, NOESY, DOSY, HSQC and HMBC NMR experiments at various temperatures with recording in "high-speed" mode. Coordination of the aldehyde to the gallium atom and formation of complexes 7 have been additionally confirmed by diffusion-ordered NMR experiments (DOSY). In this case, the 
aldehyde is coordinated quite weakly and the signals in the ${ }^{1} \mathrm{H}$ and ${ }^{13} \mathrm{C}$ NMR spectra almost do not shift. The complex is unstable and apparently exists in equilibrium with the free aldehyde.

\section{Conclusions}

Thus, we have discovered a new method to regulate the diastereoselectivity of dimerization of donor-acceptor cyclopropanes by means of ligand control. The method has been demonstrated for [4+2]-cyclodimerization of 2-(1-naphthyl)cyclopropanedicarboxylate to give polysubstituted tetrahydrophenanthrenes in the presence of gallium trichloride as an example. It has been shown that trans,trans-isomer $\mathbf{2 a}$ is formed exclusively if tetrahydrofuran is used as the ligand, whereas replacement of the ligand by an aromatic aldehyde results in predominant formation of the trans,cis-isomer. The best diastereoselectivity values are attained using pyrene-1carboxaldehyde. A possible mechanism of diastereoselectivity change has been suggested. This effect of the ligand on the reaction diastereoselectivity is of considerable interest in synthesis as it opens rather a simple way to control the diastereomeric composition of the products without changing the overall process regioselectivity.

\section{Experimental Section}

General. All reagents and solvents were used commercial grade chemicals without additional purification. All operations with $\mathrm{GaCl}_{3}$ were carried out under dry argon atmosphere. TLC analysis was performed on Silufol chromatographic plates. For preparative chromatography, silica gel $60(0.040-0.063 \mathrm{~mm})$ was used. ${ }^{1} \mathrm{H}$ and ${ }^{13} \mathrm{C}$ NMR spectra were recorded on a $400 \mathrm{MHz}$ (400.1 and $100.6 \mathrm{MHz}$, respectively) and $300 \mathrm{MHz}$ (300.1 and $75.5 \mathrm{MHz}$, respectively) spectrometers in $\mathrm{CDCl}_{3}$ containing $0.05 \% \mathrm{Me}_{4} \mathrm{Si}$ as the internal standard. Determinations of structures and stereochemistry of obtained compounds and assignments of ${ }^{1} \mathrm{H}$ and ${ }^{13} \mathrm{C}$ signals were made by 2D COSY, NOESY, DOSY, HSQC and HMBC NMR experiments. IR spectra were obtained on a FT-IR spectrometer in $\mathrm{CHCl}_{3}$ solution (0.5-2\%). High resolution mass spectra were obtained using simultaneous electospray (ESI).

General procedures for the synthesis of dimers $4 \mathrm{a}$ and $4 \mathrm{~b}$. All operations were performed in dry argon atmosphere. Anhydrous $\mathrm{GaCl}_{3}$ should be very high quality (in ampoules, with 99.999\% purity) for successful implementation of described reactions. The solid $\mathrm{GaCl}_{3}(0.4$ $\mathrm{mmol}$ ) in one portion was added at $0-5{ }^{\circ} \mathrm{C}$ to a stirring solution of 2-(naphth-1-yl)cyclopropane1,1-dicarboxylate $\mathbf{1 b}(0.4 \mathrm{mmol})$ in $4 \mathrm{~mL}$ of dry dichloromethane and the reaction mixture was stirred at the same temperature during 6-10 min for the generation of 1,2-zwitterion gallium complex 5. After that a solution of THF (1 eq) or arylcarboxaldehyde $(1.2-2.5 \mathrm{eq})$ and cyclopropane $\mathbf{1 b}(0.4 \mathrm{mmol}$, Method A) or $\beta$-naphthylvinylmalonate $(0.4 \mathrm{mmol}$, Method B) in 1 
$\mathrm{mL}$ of dry dichloromethane (1,2-dichloroethane) was added in one portion, and the reaction mixture was stirred at the $40{ }^{\circ} \mathrm{C}$ during $40-50 \mathrm{~min}$ or at the $80{ }^{\circ} \mathrm{C}$ during $1 \mathrm{~h}$ in the case of anthracene-9-carboxaldehyde or pyrene-1-carboxaldehyde. After the reaction was complete an aqueous solution of $\mathrm{HCl}(5 \%)$ was added at room temperature until $\mathrm{pH} 2-3$ was achieved and then reaction mixture was extracted with dichloromethane $(3 \times 10 \mathrm{~mL})$. The organic layer was dried over $\mathrm{MgSO}_{4}$ and the solvent was removed in vacuo. The residue was separated by column chromatography on silica gel (eluent - benzene to benzene-EtOAc, 5:1) to afford cyclopropane dimers $\mathbf{4 a}$ and $\mathbf{4 b}$, which can be additionally purified (if it is necessary) on a Silufol chromatographic plate $(20 \times 20 \mathrm{~cm})$ eluting with hexane-acetone, $5: 1$ or benzene-EtOAc, 10:1 to afford the pure products. The results obtained are given in Table 1. Spectral data for isomer 4a see in Ref. ${ }^{31}$

(1SR,2SR,3SR)-1,3-Di(1,3-dimethoxy-1,3-dioxopropan-2-yl)-2-(naphthalen-1-yl)-1,2,3,4tetrahydrophenanthrene (4b). Colorless thick oil. IR $\left(\mathrm{CHCl}_{3}\right)$ v 3029, 3021, 3017, 3012, 2955 , 2929, 2847, 1752, 1733 (C=O), 1626, 1599, 1512, 1494, 1436, 1399, 1313, $1264 \mathrm{~cm}^{-1} .{ }^{1} \mathrm{H}$ NMR $\left(\mathrm{CDCl}_{3}, 400.1 \mathrm{MHz}\right) \delta 3.11\left(\mathrm{~d}, 1 \mathrm{H}, \mathrm{H}(12),{ }^{3} J 10.0 \mathrm{~Hz}\right), 3.14\left(\mathrm{dd}, 1 \mathrm{H}, \mathrm{H}(4)-a,{ }^{2} J 19.4 \mathrm{~Hz},{ }^{3} J 12.3\right.$ $\mathrm{Hz}$ ), 3.41-3.54 (m, 2H, $\mathrm{H}(3)$ and $\mathrm{H}(4)-b), 3.438,3.444,3.69$ and 3.92 (all s, $4 \times 3 \mathrm{H}, 4 \mathrm{CO}_{2} \mathrm{Me}$ ), 4.05-4.14 (m, 2H, H(1) and H(11)), 4.56 (br.d, 1H, H(2), $\left.{ }^{3} J 3.6 \mathrm{~Hz}\right), 6.83$ (dd, 1H, H(2'), ${ }^{3} J 7.4$ $\mathrm{Hz},{ }^{4} J 1.0 \mathrm{~Hz}$ ), 7.04 (dd, 1H, H(3'), ${ }^{3} J 8.2$ and $\left.7.4 \mathrm{~Hz}\right), 7.14$ (d, 1H, H(10), ${ }^{3} J 8.6 \mathrm{~Hz}$ ), 7.46 (ddd, $1 \mathrm{H}, \mathrm{H}\left(6^{\prime}\right),{ }^{3} J 8.3$ and $\left.6.9 \mathrm{~Hz},{ }^{4} J 1.0 \mathrm{~Hz}\right), 7.49-7.55(\mathrm{~m}, 1 \mathrm{H}, \mathrm{H}(7)), 7.52-7.57\left(\mathrm{~m}, 1 \mathrm{H}, \mathrm{H}\left(7^{\prime}\right)\right)$, 7.54-7.59 (m, 1H, H(6)), 7.62 (br.d, 1H, H(9), ${ }^{3} J 8.6 \mathrm{~Hz}$ ), 7.63 (br.d, $1 \mathrm{H}, \mathrm{H}\left(4^{\prime}\right.$ ) , $\left.{ }^{3} J 8.2 \mathrm{~Hz}\right), 7.81$ (br.dd, 1H, H(5'), ${ }^{3} J 8.3 \mathrm{~Hz},{ }^{4} J 1.3 \mathrm{~Hz}$ ), 7.83 (br.dd, 1H, H(8), ${ }^{3} J 8.1 \mathrm{~Hz},{ }^{4} J 1.4 \mathrm{~Hz}$ ), 8.00 (br.d, $\left.1 \mathrm{H}, \mathrm{H}(5),{ }^{3} \mathrm{~J} 8.4 \mathrm{~Hz}\right), 8.12$ (br.d, $\left.1 \mathrm{H}, \mathrm{H}\left(8^{\prime}\right),{ }^{3} \mathrm{~J} 8.6 \mathrm{~Hz}\right) .{ }^{13} \mathrm{C} \mathrm{NMR}\left(\mathrm{CDCl}_{3}, 100.6 \mathrm{MHz}\right) \delta 26.6$ $\left(\mathrm{CH}_{2}(4)\right), 33.2(\mathrm{CH}(3)), 35.8(\mathrm{CH}(2)), 45.6(\mathrm{CH}(1)), 52.37,52.41,52.7$ and $53.0(4 \mathrm{OMe}), 54.9$ (CH(12)), 59.0 (CH(11)), 123.2 (CH(5)), 123.3 (CH(8`)), $125.2\left(\mathrm{CH}\left(2^{\prime}\right)\right), 125.4\left(\mathrm{CH}\left(3^{\prime}\right)\right), 125.5$ $\left(\mathrm{CH}\left(6^{\prime}\right)\right), 125.8\left(\mathrm{CH}\left(7^{\prime}\right)\right), 126.2\left(\mathrm{CH}\left(7^{\prime}\right)\right), 126.4(\mathrm{CH}(6)), 126.7(\mathrm{CH}(9)), 127.8\left(\mathrm{CH}\left(4^{\prime}\right)\right), 128.1$ (CH(10)), 128.8 (CH(5)), 129.2 (CH(8)), 131.0 (C(4a)), 131.9 (C(4b)), 132.6 (C(10a)), 132.8 $\left(\mathrm{C}\left(8 \mathrm{a}^{\prime}\right)\right), 132.9(\mathrm{C}(8 \mathrm{a})), 134.2\left(\mathrm{C}\left(4 \mathrm{a}^{\prime}\right)\right), 136.6\left(\mathrm{C}\left(1^{\prime}\right)\right), 168.73,168.76,168.9$ and 169.1 (4 COO). MS (m/z, \%): $568\left(1, \mathrm{M}^{+}\right), 436$ (3), 394 (1), 376 (1), 345 (2), 317 (10), 304 (100), 289 (11), 249 (7), 221 (6), 189 (8), 178 (13), 165 (66), 152 (28), 141 (35), 128 (12), 115 (11), 100 (26), 69 (27), 59 (55), 44 (39). HRMS calcd for $\mathrm{C}_{34} \mathrm{H}_{32} \mathrm{O}_{8}: M+N_{4}, 586.2435 ; M+N a, 591.1989 ; M+K$, 607.1729. Found: $m / z$ 586.2426, 591.1985, 607.1730.

\section{Acknowledgements}

This work was supported by the Russian Science Foundation (grant no. 14-13-01054).

We are grateful to Prof. Dr. V. P. Timofeev (V. A. Engelhardt Institute of Molecular Biology, Moscow) for supervising of the studies on NMR spectrometers. 


\section{References}

1. Reissig, H. U.; Zimmer, R. Chem. Rev. 2003, 103, 1151.

http://dx.doi.org/10.1021/cr010016n

2. Yu, M.; Pagenkopf, B. L. Tetrahedron 2005, 61, 321.

http://dx.doi.org/10.1016/j.tet.2004.10.077

3. de Simone, F.; Waser, J. Synthesis 2009, 20, 3353.

http://dx.doi.org/10.1055/s-0029-1216998

4. Carson, C. A.; Kerr, M. A. Chem. Soc. Rev. 2009, 38, 3051.

http://dx.doi.org/10.1039/B901245C

5. Campbell, M. J.; Johnson, J. S.; Parsons, A. T.; Pohlhaus, P. D.; Sanders, S. D. J. Org. Chem. 2010, 75, 6317.

http://dx.doi.org/10.1021/jo1010735

6. Melnikov, M. Y.; Budynina, E. M.; Ivanova, O. A.; Trushkov, I. V. Mendeleev Commun. 2011, 21, 293.

http://dx.doi.org/10.1016/j.mencom.2011.11.001

7. Schneider, T. F.; Kaschel J.; Werz, D. B. Angew. Chem. Int. Ed. 2014, 53, 5504.

http://dx.doi.org/10.1002/anie.201309886

8. de Nanteuil, F.; de Simone, F.; Frei, R.; Benfatti, F.; Serrano E.; Waser, J. Chem. Commun. 2014, 50, 10912.

http://dx.doi.org/10.1039/C4CC03194F

9. Novikov, R. A.; Tomilov, Y. V. Mendeleev Commun. 2015, 25, 1.

http://dx.doi.org/10.1016/j.mencom.2015.01.001

10. Garve, L. K. B.; Pawliczek, M.; Wallbaum, J.; Jones, P. G.; Werz, D. B. Chem. Eur. J. 2016, $22,521$.

http://dx.doi.org/10.1002/chem.201504013

11. Novikov, R. A.; Tarasova, A. V.; Korolev, V. A.; Shulishov, E. V.; Timofeev, V. P.; Tomilov, Y. V. J. Org. Chem. 2015, 80, 8225.

http://dx.doi.org/10.1021/acs.joc.5b01179

12. Wang, Z.; Chen, S.; Ren, J.; Wang Z. Org. Lett. 2015, 17, 4184.

http://dx.doi.org/10.1021/acs.orglett.5b01928

13. Ma, W.; Fang, J.; Ren, J.; Wang, Z. Org. Lett. 2015, 17, 4180.

http://dx.doi.org/10.1021/acs.orglett.5b01927

14. Liu, H.; Yuan, C.; Wu, Y.; Xiao, Y.; Guo H. Org. Lett. 2015, 17, 4220.

http://dx.doi.org/10.1021/acs.orglett.5b02003

15. Liu, Q.-J.; Yan, W.-G.; Wang, L.; Zhang, X. P.; Tang, Y. Org. Lett. 2015, 17, 4014.

http://dx.doi.org/10.1021/acs.orglett.5b01909

16. Cheng, Q.-Q.; Qian, Y.; Zavalij, P. Y.; Doyle, M. P. Org. Lett. 2015, 17, 3568.

http://dx.doi.org/10.1021/acs.orglett.5b01674

17. Ghosh, A.; Pandey, A. K.; Banerjee, P. J. Org. Chem. 2015, 80, 7235. 


\section{http://dx.doi.org/10.1021/acs.joc.5b00705}

18. Xu, H.; Hu, J.-L.; Wang, L.; Liao, S.; Tang Y. J. Am. Chem. Soc. 2015, 137, 8006. http://dx.doi.org/10.1021/jacs.5b04429

19. Rakhmankulov, E. R.; Ivanov, K. L.; Budynina, E. M.; Ivanova, O. A.; Chagarovskiy, A. O.; Skvortsov, D. A.; Latyshev, G. V.; Trushkov, I. V.; Melnikov, M. Y. Org. Lett. 2015, 17, 770 .

http://dx.doi.org/10.1021/o15037562

20. Tabolin, A. A.; Novikov, R. A.; Khomutova, Y. A.; Zharov, A. A.; Stashina, G. A.; Nelyubina, Y. V.; Tomilov, Y. V.; Ioffe, S. L. Tetrahedron Lett. 2015, 56, 2102. http://dx.doi.org/10.1016/j.tetlet.2015.03.011

21. Ivanov, K. L.; Villemson, E. V.; Budynina, E. M.; Ivanova, O. A.; Trushkov, I. V.; Melnikov, M. Y. Chem. Eur. J. 2015, 21, 4975. http://dx.doi.org/10.1002/chem.201405551

22. Ivanova, O. A.; Budynina, E. M.; Chagarovskiy, A. O.; Trushkov, I. V.; Melnikov, M. Y. J. Org. Chem. 2011, 76, 8852. http://dx.doi.org/10.1021/jo201612w

23. Chagarovskiy, A. O.; Ivanova, O. A.; Budynina, E. M.; Trushkov, I. V.; Melnikov, M. Y. Tetrahedron Lett. 2011, 52, 4421. http://dx.doi.org/10.1016/j.tetlet.2011.06.059

24. Novikov, R. A.; Tarasova, A. V.; Tomilov, Y. V. Mendeleev Commun. 2015, 25, 341. http://dx.doi.org/10.1016/j.mencom.2015.09.007

25. Novikov, R. A.; Korolev, V. A.; Timofeev, V. P.; Tomilov, Y. V. Tetrahedron Lett. 2011, $52,4996$.

http://dx.doi.org/10.1016/j.tetlet.2011.07.001

26. Ivanova, O. A.; Budynina, E. M.; Khrustalev, V. N.; Trushkov, I. V.; Melnikov, M. Y. Chem. Heterocyclic Comp. 2015, 51, 936. http://dx.doi.org/10.1007/s10593-015-1798-y

27. Ivanova, O. A.; Budynina, E. M.; Khrustalev, V. N.; Skvortsov, D. A.; Trushkov, I. V.; Melnikov, M. Y. Chem. Eur. J. 2016, 22, 1223.

http://dx.doi.org/10.1002/chem.201502287

28. Ivanova, O. A.; Budynina, E. M.; Chagarovskiy, A. O.; Rakhmankulov, E. R.; Trushkov, I. V.; Semeykin, A. V.; Shimanovskii, N. L.; Melnikov, M. Y. Chem. Eur. J. 2011, 17, 11738. http://dx.doi.org/10.1002/chem.201101687

29. Novikov, R. A.; Tomilov, Y. V. Helv. Chim. Acta 2013, 96, 2068. http://onlinelibrary.wiley.com/doi/10.1002/hlca.201200636/full

30. Ivanova, O. A.; Budynina, E. M.; Skvortsov, D. A.; Limoge, M.; Bakin, A. V.; Chagarovskiy, A. O.; Trushkov, I. V.; Melnikov, M. Y. Chem. Commun. 2013, 49, 11482. http://dx.doi.org/10.1039/C3CC44475A

31. Novikov, R. A.; Tarasova, A. V.; Korolev, V. A.; Timofeev V. P.; Tomilov, Y. V. Angew. Chem. Int. Ed. 2014, 53, 3187. 
http://dx.doi.org/10.1002/anie.201306186

32. Novikov, R. A.; Balakirev, D. O.; Timofeev, V. P.; Tomilov, Y. V. Organometallics 2012, $31,8627$. http://dx.doi.org/10.1021/om301072v

33. Chagarovskiy, A. O.; Ivanova, O. A.; Rakhmankulov, E. R.; Budynina, E. M.; Trushkov, I. V.; Melnikov, M. Y. Adv. Synth. Catal. 2010, 352, 3179. http://dx.doi.org/10.1002/adsc.201000636

34. Pohlhaus, P. D.; Johnson, J. S. J. Am. Chem. Soc. 2005, 127, 16014. http://dx.doi.org/10.1021/ja055777c

35. Pohlhaus, P. D.; Sanders, S. D.; Parsons, A. T.; Li, W.; Johnson, J. S. J. Am. Chem. Soc. 2008, 130,8642 .

http://dx.doi.org/10.1021/ja8015928

36. Racine, S.; de Nanteuil, F.; Serrano, E.; Waser, J. Angew. Chem. Int. Ed. 2014, 53, 8484. http://dx.doi.org/10.1002/anie.201404832

37. Yang, G.; Shen, Y.; Li, K.; Sun, Y.; Hua, Y. J. Org. Chem. 2011, 76, 229. http://dx.doi.org/10.1021/jo1020773

38. Smith, A. G.; Slade, M. C.; Johnson, J. S. Org. Lett. 2011, 13, 1996. http://dx.doi.org/10.1021/ol200395e

39. Xing, S.; Li, Y.; Li, Z.; Liu, C.; Ren, J.; Wang, Z. Angew. Chem. Int. Ed. 2011, 50, 12605. http://dx.doi.org/10.1002/anie.201106368 